\title{
The Prevalence of Erosive Esophagitis Is Not Significantly Increased in a Healthy Korean Population - Could It Be Explained?: A Multi-center Prospective Study
}

\author{
Geom Seog Seo, ${ }^{1}$ Byung Jun Jeon, ${ }^{1}$ Jin Soo Chung, ${ }^{1}$ Young-Eun Joo, ${ }^{2}$ Gwang Ha Kim ${ }^{3 *}$ Gwang Ho Baik, ${ }^{4 *}$ Dae Yong Kim, ${ }^{4}$ \\ Jeong Eun Shin, ${ }^{5}$ Heung Up Kim, ${ }^{6}$ Hyun Kyung Park ${ }^{7}$ and Nayoung Kim ${ }^{7}$ \\ ${ }^{1}$ Department of Internal Medicine, Digestive Disease Research Institute, Wonkwang University College of Medicine, Iksan, Jeollabuk-do, \\ Korea; ' Department of Internal Medicine, Chonnam National University Medical School, Gwangju, Korea; ${ }^{3}$ Department of Internal Medicine, \\ Pusan National University School of Medicine, Busan, Korea; ${ }^{4}$ Department of Internal Medicine, Hallym University College of Medicine, \\ Chuncheon, Gangwon-do, Korea; ${ }^{5}$ Department of Internal Medicine, Dankook University College of Medicine, Cheonan, Chungcheong- \\ nam-do, Korea; 'Department of Internal Medicine, Jeju National University College of Medicine, Jeju, Korea; and ${ }^{7}$ Department of Internal \\ Medicine, Seoul National University Bundang Hospital, Seongnam, Gyeonggi-do, Korea
}

\section{Background/Aims}

Researches on the potential risk factors for the development of erosive esophagitis have been conducted extensively, however, the results are conflicting. The aim of this multicenter study was to identify the prevalence rate and risk factors of erosive esophagitis and their interactions with residency status.

Methods

A total of 4,023 eligible subjects at 8 tertiary health care centers were evaluated using questionnaires, laboratory tests and endoscopy. Univariate and multivariate analyses were conducted to identify independent risk factors for erosive esophagitis.

Results

The prevalence rate of reflux esophagitis was $8.8 \%$. Los Angeles grade A was common type of erosive esophagitis. Residence in a large urban areas was negatively associated with the development of erosive esophagitis $(0 R, 0.60 ; 95 \% \mathrm{Cl}, 0.40-0.90)$. The high body mass index $\left(\geq 25 \mathrm{~kg} / \mathrm{m}^{2}\right)$ was more frequent in residents of small and medium-sized cities than those in big cities $(38.8 \%$ and $26.9 \%$, respectively; $P<0.001)$. Seronegativity of Helicobacter pylori was associated with increased erosive esophagitis $(O R, 1.91 ; 95 \% \mathrm{Cl}, 1.48-2.46)$. Triglyceride $\geq 150 \mathrm{mg} / \mathrm{dL}(O R, 1.65 ; 95 \% \mathrm{Cl}, 1.08-2.07)$, fasting glucose level $\geq$ $126 \mathrm{mg} / \mathrm{dL}(\mathrm{OR}, 1.73 ; 95 \% \mathrm{Cl}, 1.06-2.81)$, and hiatal hernia (OR, 3.11; 95\% Cl, 1.87-5.16) were also associated with erosive esophagitis.

\section{Conclusions}

The prevalence rate of erosive esophagitis and its risk factors in this study were similar to the result of $8.0 \%$ of nationwide study in 2006. Residency and obesity are more important independent risk factors than $H$. pylori infection status for development of erosive esophagitis in Korea. These results suggest that the prevalence rate of erosive esophagitis in Korea might not increase as in the Western countries.

(J Neurogastroenterol Motil 2013;19:70-77)

Key Words

Esophagitis; Helicobacter pylori; Risk factors

Received: September 24, 2012 Revised: December 3, 2012 Accepted: December 4, 2012

(c) This is an Open Access article distributed under the terms of the Creative Commons Attribution Non-Commercial License (http://creativecommons. org/licenses/by-nc/3.0) which permits unrestricted non-commercial use, distribution, and reproduction in any medium, provided the original work is properly cited.

*Correspondence: Gwang Ho Baik, MD

Department of Internal Medicine, Hallym University College of Medicine, 77, Sakju-ro, Chuncheon, Gangwon-do 200-704, Korea Tel: +82-33-240-5810, Fax: +82-33-241-8064, E-mail: baikgh@hallym.or.kr

Gwang Ha Kim, MD

Department of Internal Medicine, Pusan National University School of Medicine, 179, Gudeok-ro, Seo-gu, Busan 602-739, Korea Tel: +82-51-240-7869, Fax: +82-51-244-8180, E-mail: doc0224@pusan.ac.kr

Gwang Ho Baik and Gwang Ha Kim are equally responsible for this study.

Financial support: This study was supported by Wonkwang University in 2012.

Conflicts of interest: None.

Author contributions: Geom Seog Seo, Young-Eun Joo, Gwang Ha Kim, Gwang Ho Baik, Jeong Eun Shin, Heung Up Kim and Nayoung Kim made substantial contribution to the conception and design of the study, the acquistion of the data and analysis and interpretation of the data, and wrote the paper. Byung Jun Jeon, Jin Soo Chung, Dae Yong Kim and Hyun Kyung Park contributed to collection and drafting the manuscript. 


\section{Introduction}

Endoscopy-diagnosed erosive esophagitis has been increasing in Asia over 2 decades, with a reported prevalence of 3.3 to $8.5 \%$ in Korea, China and Japan except Taiwan (ranging from 17.3 to $18.3 \%$ ) which is similar to other Western developed countries. $^{1-6}$ The reasons for the high prevalence rate of erosive esophagitis are not clearly demonstrated, however, it could be related with western diet, increased obesity and aging of population. ${ }^{6}$ The prevalence rate of erosive esophagitis was $8 \%$, in prospective nationwide multicentre studies of 25,536 health check-up Koreans. ${ }^{7}$ This prevalence rate was lower than that in Western countries. ${ }^{8}$ Association between high Helicobacter pylori infectivity and relatively low obesity rate has long been expected to maintain low prevalence of erosive esophagitis in Koreans.

The potential risk factors of erosive esophagitis are hiatal hernia, gender, hyperlipidemia, diabetes, alcohol, smoking, as well as H. pylori infection and obesity. Among them, H. pylori infection and obesity status are important on the prevalence of reflux esophagitis and have been studied throughout Asia. ${ }^{910}$ H. pylori seropositivity has been known to protect against gastroesophageal reflux in Asia, especially in the Far East. ${ }^{11-13}$ Furthermore, patients with $H$. pylori infection have less severe gastroesophageal reflux disease, ${ }^{14,15}$ however, $H$. pylori infection does not always influence gastroesophageal reflux disease, and the effect of eradication of $H$. pylori on reflux esophagitis is controversial. ${ }^{16-20}$ Given the regional differences in seroprevalence of $H$. pylori in Korea, ${ }^{21}$ multicenter, prospective studies on the risk factors of reflux esophagitis seem to be important.

Recently there was a increase in obese patients as defined by those with body mass index (BMI) greater than $25 \mathrm{~kg} / \mathrm{m}^{2}$ in Koreans which are lower than that in the Western countries. ${ }^{22}$ Korea Centers for Disease Control and Prevention studied urban and rural patients with obesity and reported a signigicant differences, namely, $30.3 \%$ and $36.5 \%$, respectively. ${ }^{23}$ Thus, we need to know the change of seroprevalence of $H$. pylori and obesity influencing erosive esophagitis as well as other risk factors compared with previous Korean data. And also, by our data obtained from 8 health promotion centers, risk factor analysis of erosive esophagitis according to dwelling places is useful in elucidation of environmenal factors.

Therefore, we conducted this prospective multi-center study to investigate the interval change of prevalence of erosive esophagitis in healthy subjects and to find risk factors related to erosive esophagitis according to dwelling places.

\section{Materials and Methods}

\section{Study Sample}

A prospective study was carried out from January 2011 through December 2011 at 8 healthcare centers throughout Korea. Individuals with a history of gastrointestinal surgery or systemic diseases requiring chronic medication except hypertension and diabetes mellitus were excluded. This study was reviewed and approved by the Institutional review boards of the participating hospitals, and all participating subjects provided their written, informed consent. Residency status was divided into 2 types, according to big cities (Gyeonggi and Busan) and small and medium cities (Jeolla, Chungcheong, Gangwon and Jeju).

\section{Questionnaire}

Before endoscopy, clinical interviews based on a structured questionnaire were conducted, under the supervision of a well trained interviewer, to assess personal and clinical data of all subjects. The questionnaire included questions about demographic data, presence of upper gastrointestinal symptoms, comorbidities, history of $H$. pylori eradication, drug history including NSAIDs and antibiotics, alcohol consumption, smoking history, consumption of dairy products, and family history of gastric cancer. ${ }^{21} \mathrm{BMI}$, cholesterol, triglyceride (TG), glucose level and H. pylori infection status were recorded.

\section{Endoscopic Findings}

Endoscopic reflux esophagitis was diagnosed if definite erosions were present. Minimal change esophagitis was excluded because of weak interobserver agreement. ${ }^{24}$ The severity of esophagitis was graded from A through D, according to the Los Angeles (LA) classification. ${ }^{25}$ The presence of hiatal hernia was endoscopically diagnosed if the distance from the esophagogastric junction to the diaphragmatic impingement was more than $1 \mathrm{~cm}$. The esophagogastric junction is defined as the proximal margin of the gastric mucosal fold. Edematous longitudinal fold of gastric mucosa taking a polypoid form was diagnosed as sentinel polyp. Benign peptic esophageal stricture was measured endoscopically and radiologically. Barrett's esophagus was suspected when endoscopic findings in the distal esophagus appeared to suggest gastric metaplasia, for example, salmon-pink colored columnar esophagus or presence of tongue-like projections.

\section{Helicobacter pylori Serology Examination}

Blood samples were collected from all participants before 
endoscopy. The samples were immediately centrifuged and stored at $-70^{\circ} \mathrm{C}$. Assessment of $H$. pylori infection was based on enzyme-linked immunosorbent assay (ELISA) for anti-H. pylori
IgG using a Genedia kit (Genedia H. pylori ELISA; Green Cross Medical Science Corp, Eumsung, Korea) and duplicate determinations according to the manufacturer's guidelines. The

Table 1. Baseline Characteristics Between Subjects With Reflux Esophagitis and Those Without Reflux Esophagitis

\begin{tabular}{|c|c|c|c|c|}
\hline \multirow{2}{*}{ Variable } & \multicolumn{2}{|c|}{ Reflux esophagitis } & \multirow{2}{*}{$\begin{array}{c}\text { Total } \\
(\mathrm{N}=4,023)\end{array}$} & \multirow{2}{*}{$P$-value } \\
\hline & Absent $(\mathrm{n}=3,669)$ & Present $(\mathrm{n}=354)$ & & \\
\hline Gender (n [\%]) & & & & $<0.000$ \\
\hline Male & $2,087(56.9)$ & $271(76.6)$ & $2,358(58.6)$ & \\
\hline Female & $1,582(33.1)$ & $83(23.4)$ & $1,665(41.4)$ & \\
\hline Age (n [\%], yr) & & & & 0.741 \\
\hline$\leq 39$ & $789(21.5)$ & $76(21.5)$ & $865(21.5)$ & \\
\hline $40-59$ & $2,261(61.6)$ & $225(63.5)$ & $2,486(61.8)$ & \\
\hline$\geq 60$ & $619(16.9)$ & $53(15.0)$ & $672(16.7)$ & \\
\hline H. pylori $\operatorname{IgG}(\mathrm{n}[\%])$ & & & & $<0.000$ \\
\hline Positive & $2,249(61.3)$ & $158(44.6)$ & $2,407(59.8)$ & \\
\hline Negative & $1,420(38.7)$ & $196(55.4)$ & $1,616(40.2)$ & \\
\hline Hital hernia (n [\%]) & & & & $<0.000$ \\
\hline Yes & $74(2.0)$ & $32(9.0)$ & $106(2.6)$ & \\
\hline No & $3,595(98.0)$ & $322(91.0)$ & $3,917(97.4)$ & \\
\hline Barrett's esophagus (n [\%]) & & & & 0.037 \\
\hline Yes & $24(0.7)$ & $6(1.7)$ & $30(0.75)$ & \\
\hline No & $3,613(99.3)$ & $348(98.3)$ & $3,961(99.25)$ & \\
\hline $\mathrm{BMI}\left(\mathrm{n}[\%], 25 \mathrm{~kg} / \mathrm{m}^{2}\right)$ & & & & 0.003 \\
\hline$<23$ & $1,432(39.5)$ & $87(24.7)$ & $1,519(38.2)$ & \\
\hline$\geq 23,<25$ & $944(26.1)$ & $90(25.6)$ & $1,034(26.0)$ & \\
\hline$\geq 25$ & $1,246(34.4)$ & $175(49.7)$ & $1,421(35.8)$ & \\
\hline Cholesterol (n [\%], mg/dL) & & & & 0.820 \\
\hline$<200$ & $1,695(58.5)$ & $173(59.4)$ & $1,868(58.6)$ & \\
\hline$\geq 200,<240$ & $886(30.6)$ & $93(32.0)$ & $979(30.7)$ & \\
\hline$\geq 240$ & $317(10.9)$ & $25(8.6)$ & $342(10.7)$ & \\
\hline Triglyceride (mg/dL) & & & & $<0.000$ \\
\hline$<150$ & 2,196 & 171 & $2,367(74.2)$ & \\
\hline$\geq 150$ & 700 & 121 & $821(25.8)$ & \\
\hline Glucose (mg/dL) & & & & 0.007 \\
\hline$<126$ & $2,770(95.9)$ & $268(92.1)$ & $3,038(95.5)$ & \\
\hline$\geq 126$ & $119(4.1)$ & $23(7.9)$ & $142(4.5)$ & \\
\hline History of $H$. pylori eradication (n [\%]) & & & & 0.019 \\
\hline Yes & $458(12.6)$ & $60(17.0)$ & $518(13.0)$ & \\
\hline No & $3,186(87.4)$ & $293(83.0)$ & $3,479(87.0)$ & \\
\hline Alcohol consumption ( $\mathrm{n}[\%]$ ) & & & & $<0.000$ \\
\hline Yes & $1,618(45.0)$ & $224(64.4)$ & $1,842(46.85)$ & \\
\hline No & $1,975(55.0)$ & $124(35.6)$ & $2,099(53.15)$ & \\
\hline Smoking habit (n [\%]) & & & & 0.000 \\
\hline Yes & $2,426(67.3)$ & $270(77.4)$ & $2,696(68.2)$ & \\
\hline No & $1,180(32.7)$ & $79(22.6)$ & $1,259(31.8)$ & \\
\hline Urban dwelling (n [\%]) & & & & 0.043 \\
\hline Big city & $936(25.9)$ & $71(20.4)$ & $1,007(25.4)$ & \\
\hline Small and medium sized cities & $2,673(74.1)$ & $277(79.6)$ & $2,950(74.6)$ & \\
\hline
\end{tabular}

H. pylori, Helicobacter pylori; H. pylori IgG, serum H. pylori immunoglobulin G antibody; BMI, body mass index. 
Genedia kit makes use of an $H$. pylori antigen obtained from Korean $H$. pylori strains and has a sensitivity and specificity in Korean adults of $97.8 \%$ and $92.0 \%$, respectively. The cut-off optical density (OD $450 \mathrm{~nm}$ ) of $H$. pylori $\mathrm{IgG}$ was 0.406 .

\section{Statistical Methods}

Continuous variables were analyzed by Student's $t$ test. Categorical variables were analyzed using chi-square $\left(\chi^{2}\right)$ test or Fisher's exact test. Univariate logistic regression and multivariate logistic regression analysis were used for the analysis of independent risk factors, which were expressed as the odds ratio (OR) and 95\% confidence interval (CI). All $P$-values of less than 0.05 were considered statistically significant.

\section{Results}

\section{Characteristics of Participants}

Of the 4,086 patients, 4,023 were eligible for the study. Sixty-three patients were excluded because of incomplete filling of a questionnaire. Mean age was $48.7 \pm 11.3$ years, and 2,358 (58.6\%) patients were men. The clinical and demographic data of the patients are summarized in Table 1 , including sex, age, $H$. $p y$ lori IgG, hiatal hernia, Barrett's esophagus, BMI, lipid profile, glucose level, history of $H$. pylori eradication, alcohol consumption, smoking history and place of residence. H. pylori seropositivity was detected in 2,407 (59.8\%) patients. Seroprevalence of $H$. pylori was increased with older age (40-49 years, $55.5 \%$; $50-59$ years, $60.20 \%$; above 60 years, $62.6 \%$ ). There was no gender difference of $H$. pylori infection status.

\section{Prevalence and Grade of Erosive Esophagitis}

The prevalence rate of reflux esophagitis in this study was $8.8 \%$. The distibution of erosive esophagitis was LA-A (6.4\%), LA-B $(2.1 \%)$, LA-C $(0.3 \%)$ and LA-D $(0.1 \%)$. One mucosal break was more common than multiple. The degree of mucosal breaks ( $<5,5-10$ and $10-20 \mathrm{~mm}$ ) was particulary pronounced in $5 \mathrm{~mm}$ in all age groups ( $\leq 39$ years, $73.3 \%$ vs. $26.7 \%$ vs. $0.0 \%$; $40-59$ years, $72.7 \%$ vs. $21.8 \%$ vs. $3.2 \%$; $\geq 60$ years, $70 \%$ vs. $26 \%$ vs. $2 \%$ ). Absence of confluent erosions were most common in all age groups. The prevalence of erosive esophagits was higher in men than in women, especially with LA-A, LA-B and LA-C. The prevelance rate of erosive esophagitis was similar in each aging group ( $\leq 39$ years, $8.8 \%$; $40-59$ years, $9.1 \%$; $\geq 60$ years, $7.9 \%$ ) (Table 2). The prevalence of seropositivity in residents of
Table 2. Characteristics of Erosive Esophagitis Accoding to Ages

\begin{tabular}{lrrr}
\hline & \multicolumn{3}{c}{ Age (yr) } \\
\cline { 2 - 4 } & $\leq 39$ & $40-59$ & $60 \leq$ \\
\hline LA classification & & & \\
Grade A & 6.6 & 6.6 & 5.2 \\
Grade B & 2.2 & 2.1 & 2.2 \\
Grade C & 0.0 & 0.3 & 0.3 \\
Grade D & 0.0 & 0.0 & 0.1 \\
Number of mucosal breaks & & & \\
Single & 68 & 68 & 58 \\
Multiple & 32 & 32 & 42 \\
Length of mucosal breaks & & & \\
$\quad<5$ mm & 73.3 & 72.7 & 70.0 \\
5-10 mm & 26.7 & 21.8 & 26.0 \\
10-20 mm & 0.0 & 3.2 & 2.0 \\
$>20$ mm & 0.0 & 2.3 & 2.0 \\
Confluence of mucosal breaks & & & \\
None & 100.0 & 96.5 & 95.0 \\
$<75 \%$ & 0.0 & 3.5 & 2.5 \\
$\quad \geq 75 \%$ & 0.0 & 0.0 & 2.5 \\
\hline
\end{tabular}

LA classification, Los Angeles classification.

Data are present as percent.

big cities (Gyeonggi and Busan) and in small and medium cities (Jeolla, Chungcheong, Gangwon and Jeju) was $56.6 \%$ and $60.5 \%$, respectively, while the prevalence rates of reflux esophagitis was $7.1 \%$ and $9.4 \%$, respectively (Fig. 1). Endoscopically suspected Barret esophagus was 0.8\% (male, 0.9\%; female, $0.5 \%)$. Stricture was not detected and sentinel polyp was very rare $(0.1 \%)$.

\section{Risk Factors for Reflux Esophagitis}

Hiatal heria was $2.6 \%$ and had no gender difference. Small size of hiatal hernia was more common $(1 \mathrm{~cm}<$ size $\leq 2 \mathrm{~cm}$, $54.5 \%)$. Total frequency of BMI higher than $25 \mathrm{~kg} / \mathrm{m}^{2}$ was $35.8 \%$. The frequency of obesity were significantly different between big, and small and medium-sized cities (26.9\% and 38.8\%, respectively; $P<0.001$ ) (Fig. 2).

Univariate analysis identified significant differences regarding sex, H. pylori seronegativity, hiatal hernia, Barrett's esophagus, $\mathrm{BMI} \geq 25 \mathrm{~kg} / \mathrm{m}^{2}, \mathrm{TG} \geq 125 \mathrm{mg} / \mathrm{dL}$, fasting glucose level $\geq 126 \mathrm{mg} / \mathrm{dL}$, history of $H$. pylori eradication, alcohol consumption, smoking habit, residence in big cities and salty diet (Table 3). Multivariate analysis revealed that several factors were independently associated with an increased risk of reflux esophagitis: $H$. pylori seronegativity (OR, 1.91; 95\% CI, 1.48-2.46), 


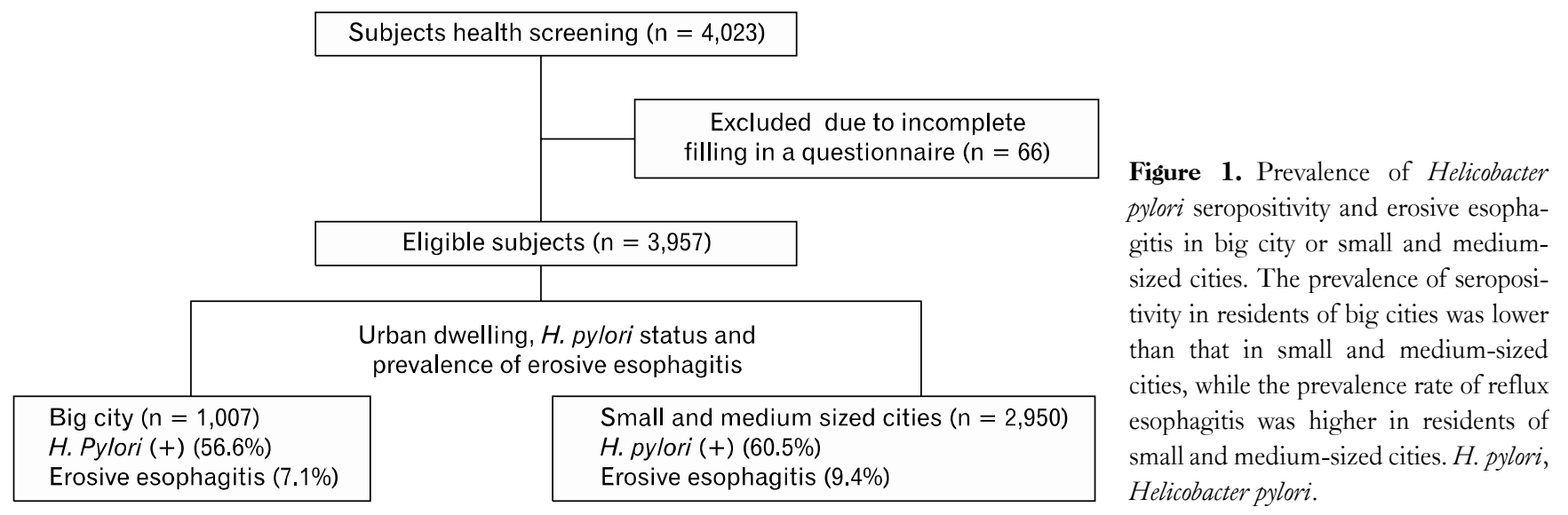

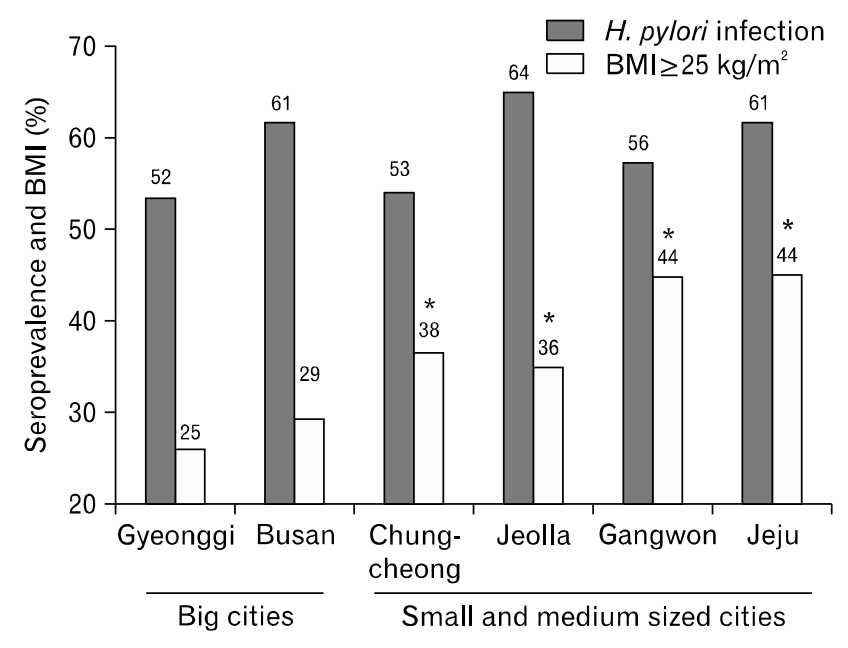

Figure 2. Comparison of seroprevalence of Helicobacter pylori infection and high body mass index (BMI) according to the geographic area. The high BMI level was more frequent in residents of small and mediumsized cities than those in big city $\left({ }^{*} P<0.001\right)$.

$\mathrm{BMI} \geq 25 \mathrm{~kg} / \mathrm{m}^{2}(\mathrm{OR}, 1.49 ; 95 \% \mathrm{CI}, 1.08-2.06), \mathrm{TG} \geq 150$ $\mathrm{mg} / \mathrm{dL}$ (OR, 1.65; 95\% CI, 1.08-1.06), fasting glucose level $\geq 126 \mathrm{mg} / \mathrm{dL}(\mathrm{OR}, 1.72 ; 95 \% \mathrm{CI}, 1.06-2.81)$ and hiatal hernia (OR, 3.10; 95\% CI, 1.86-5.16). The OR of residents in a big city for the prevalence of reflux esophagitis was 0.59 (95\% CI, 0.39-0.90) (Table 4).

\section{Discussion}

The prevalence of reflux esophagitis in Korea has increased since the 1990s. In 1999, the prevalence of reflux esophagitis in patients with gastrointestinal symptoms was $5.3 \%{ }^{26}$ The prevalence of erosive esophagitis in patients undergoing regular health check-up was $8.0 \%$ in $2006 .{ }^{7}$ In this study, the prevalence of re-
Table 3. Univariate Analysis on the Risk for Reflux Esophagitis

\begin{tabular}{lrrr}
\hline \multicolumn{1}{c}{ Variable } & OR & $95 \% \mathrm{CI}$ & $P$-value \\
\hline Gender, male & 2.46 & $1.91-3.18$ & $<0.000$ \\
H. pylori IgG negativity & 1.93 & $1.55-2.41$ & $<0.000$ \\
Hital hernia & 4.82 & $3.14-7.42$ & $<0.000$ \\
Barrett's esophagus & 2.59 & $1.05-6.39$ & 0.037 \\
BMI $\geq 25 \mathrm{~kg} / \mathrm{m}^{2}$ & 1.58 & $1.16-2.14$ & 0.003 \\
$\mathrm{TG} \geq 150 \mathrm{mg} / \mathrm{dL}$ & 2.17 & $1.69-2.78$ & $<0.000$ \\
Glucose $\geq 126 \mathrm{mg} / \mathrm{dL}$ & 1.88 & $1.18-2.98$ & 0.007 \\
History of $H$. pylori eradication & 1.42 & $1.05-1.90$ & 0.019 \\
Alcohol consumption & 2.19 & $1.74-2.75$ & $<0.000$ \\
Smoking habit & 1.66 & $1.28-2.15$ & $<0.000$ \\
Big urban dwelling & 0.76 & $0.58-0.99$ & 0.043 \\
\hline
\end{tabular}

H. pylori, Helicobacter pylori; BMI, body mass index; TG, triglyceride.

Table 4. Multivariate Analysis on the Risk for Reflux Esophagitis

\begin{tabular}{lcrr}
\hline \multicolumn{1}{c}{ Variable } & OR & $95 \% \mathrm{CI}$ & $P$-value \\
\hline H. pylori IgG negativity & 1.91 & $1.48-2.46$ & $<0.000$ \\
Big urban dwelling & 0.59 & $0.39-0.90$ & 0.014 \\
BMI $\geq 25 \mathrm{~kg} / \mathrm{m}^{2}$ & 1.49 & $1.08-2.06$ & 0.014 \\
$\mathrm{TG} \geq 150 \mathrm{mg} / \mathrm{dL}$ & 1.65 & $1.08-2.06$ & 0.000 \\
Glucose $\geq 126 \mathrm{mg} / \mathrm{dL}$ & 1.72 & $1.06-2.81$ & 0.028 \\
Hiatal hernia & 3.10 & $1.86-5.16$ & $<0.000$ \\
\hline
\end{tabular}

H. pylori, Helicobacter pylori; BMI, body mass index; TG, triglyceride.

flux esophagitis was $8.8 \%$, which is similar to the previous study.

Seroprevalence of $H$. pylori were $59.5 \%$ and $59.8 \%$ in 2005 and 2011, respectively. The relationship between $H$. pylori and reflux esophagitis is not clear yet. In a recent large case-control study, H. pylori seropositivity was inversely associated with the risk of reflux esophagitis, and the prevalence of $H$. pylori infection was lower in reflux esophagitis cases than in controls $(38.4 \%$ vs. 
$58.2 \%, P<0.001) .{ }^{13}$ In our large sample, the prevalence of $H$. pylori infection was also lower in reflux esophagitis cases than in patients without reflux esophagitis (44.6\% vs. $61.3 \%, P<$ 0.0001 ) and the OR of $H$. pylori seronegativity for the development of reflux esophagitis was 1.91 (95\% CI, 1.48-2.46). H. pylo$r i$ infection was inversely correlated with the risk of erosive esophagitis.

The association between $H$. pylori seropositivity and residence location is well known. ${ }^{21}$ According to geographic area in 2005, seroprevalence was $57.6 \%$ and $60.5 \%$ in big cities (Seoul and Gyeonggi, respectively), while higher than $60 \%$ in small and medium cities. The seroprevalence of $H$. pylori between 2005 and this study was not changed in big and small-medium cities. Differences in socioeconomic condition, sanitation and hygienic practices may explain this result. Taken together, the seroprevalence was slightly lower in big city residence than small and medium sized cities, suggesting that this difference could not explain the different prevalence rate of erosive esophagitis according to dwelling status.

Asides from $H$. pylori infection, obesity is an another major risk factor for erosive esophagitis. ${ }^{27,28}$ However, recent studies on the association between BMI and erosive esophagitis have resulted in heterogenous data. ${ }^{29-32}$ There are no large-scale prospective studies involving healthy subjects with erosive esophagitis in the aspect of dwelling places. Relationship between obesity and erosive esophagitis is well known, ${ }^{28}$ however, the gender effect is controversial. ${ }^{33-35}$ Our study showed that rate of obesity in big city dwelling was less frequent than that in small and medium cities after adjusting for potential confounding factots. According to KNHANES obseity data from 1998 to 2009 (1998, 2005 and 2007-2009), Korean with a BMI $\geq 25 \mathrm{~kg} / \mathrm{m}^{2}$ was found to be $25.9 \%, 34.8 \%$ and $35.8 \%$ in men, $27.5 \%, 28.3 \%$ and $26.1 \%$ in women, respectively. ${ }^{22}$ This result suggests that the prevalence of obesity was recently stagnated, and that there is a decreasing tendency in women. Our study shows that the prevalence rate of erosive esophagitis was lower in big city dwelling than in small and medium cities dwelling ( $7.1 \%$ and $9.4 \%$, respectively) due to less frequent rate of obesity $(P<0.001)$ and these data were obtained after adjusting for confounding factors, including $H$. pylori infection, TG, glucose and hiatal hernia. This lower rate of BMI $\geq 25 \mathrm{~kg} / \mathrm{m}^{2}$ in big city residence may be explained by the fact that they may have a chance to receive a regular private health screening and engage in regular exercise maintaining a healthy weight.
Many other studies have found that hiatal hernia is associated with a high risk of reflux esophagitis. ${ }^{36-39}$ In our study, according to univariate analysis hiatal hernia (OR, 3.02; 95\% CI, 1.87-5.16) was significantly associated with reflux esophagitis (all $P<$ 0.0001).

Factors that are consistently reported to be associated with reflux esophagitis include advanced age, diabetes, hyperlipidemia, alcohol and smoking. ${ }^{19,40-45}$ In the present study, multivariate analysis identified high TG (OR, 1.65; 95\% CI, 1.08-2.07) and elevated fasting glucose (OR, 1.73; 95\% CI, 1.06-2.81) level as risk factors. Reports of the effects of smoking and alcohol consumption on the development of reflux esophagitis have been inconsistent. ${ }^{44,45}$ In our study, according to univariate analysis alcohol consumption (OR, 2.19; 95\% CI 1.74-2.76) and smoking habit (OR, 1.66; 95\% CI, 1.28-2.16) were significantly associated with reflux esophagitis (all $P<0.0001$ ).

The present study has several potential limitations. First, 527 (13.1\%) patients with $H$. pylori eradication were included. The reasons for eradication were peptic ulcers (24.9\%), gastroduodenitis $(33.7 \%)$, patients' choice $(35.9 \%)$ and family history of gastric cancer (2.6\%). However, these subjects were equally distributed among cases and controls and there was no statistically significant difference between patients with and without reflux esophagitis, with respect to $H$. pylori eradication. Second, $H$. pylori infection status was evaluated only by serologic testing. Therefore, we did not assess the current or past infection status. Third, analysis of risk factors did not take into account the severity of reflux esophagitis.

In conclusion, the prevalence rate of erosive esophagitis and its risk factors in this study were similar to nationwide study in 2006. H. pylori seropositivity and residence in a large city were inversely related to the risk of reflux esophagitis in a large-sample, multicenter study of the Korean population. The degree and duration of obesity would be important risk factor for the development of erosive esophagitis in the future. Factors associated with metabolic syndrome including high TG and elevated fasting glucose level and hiatal hernia were also related to the risk of reflux esophagitis.

This study is meaningful in that as it has provided clues regarding the prevalence of erosive esophagitis and risk factors in healthy subjects. Further studies are necessary to determine the potential risk factors for the development of erosive esophagitis and we should pay attention to the changes in the prevalence of obesity in Koreans. 


\section{References}

1. Kang JY, Tay HH, Yap I, Guan R, Lim KP, Math MV. Low frequency of endoscopic esophagitis in Asian patients. J Clin Gastroenterol 1993;16:70-73.

2. Mishima I, Adachi K, Arima N, et al. Prevalence of endoscopically negative and positive gastroesophageal reflux disease in the Japanese. Scand J Gastroenterol 2005;40:1005-1009.

3. Lee YC, Wang HP, Chiu HM, et al. Comparative analysis between psychological and endoscopic profiles in patients with gastroesophageal reflux disease: a prospective study based on screening endoscopy. J Gastroenterol Hepatol 2006;21:798-804.

4. Dent J, Becher A, Sung J, Zou D, Agréus L, Bazzoli F. Systematic review: patterns of reflux-induced symptoms and esophageal endoscopic findings in large-scale surveys. Clin Gastroenterol Hepatol 2012;10:863-873. e3.

5. Chen TS, Chang FY. The prevalence and risk factors of reflux esophagitis among adult Chinese population in Taiwan. J Clin Gastroenterol 2007;41:819-822.

6. Ou JL, Tu CC, Hsu PI, et al. Prevalence and risk factors of erosive esophagitis in Taiwan. J Chin Med Assoc 2012;75:60-64.

7. Kim N, Lee SW, Cho SI, et al. The prevalence of and risk factors for erosive oesophagitis and non-erosive reflux disease: a nationwide multicentre prospective study in Korea. Aliment Pharmacol Ther 2008;27:173-185.

8. Lee SP, Lee KN, Lee OY, et al. The relationship between existence of typical symptoms and psychological factors in patients with erosive esophagitis. J Neurogastroenterol Motil 2012;18:284-290.

9. Goh KL. Gastroesophageal reflux disease in Asia: A historical perspective and present challenges. J Gastroenterol Hepatol 2011; 26(suppl 1):2-10.

10. Wu JC. Gastroesophageal reflux disease: an Asian perspective. J Gastroenterol Hepatol 2008;23:1785-1793.

11. Zou D, He J, Ma X, et al. Epidemiology of symptom-defined gastroesophageal reflux disease and reflux esophagitis: the systematic investigation of gastrointestinal diseases in China (SILC). Scand J Gastroenterol 2011;46:133-141.

12. Gunji T, Sato H, Iijima K, et al. Risk factors for erosive esophagitis: a cross-sectional study of a large number of Japanese males. J Gastroenterol 2011;46:448-455.

13. Chung SJ, Lim SH, Choi J, et al. Helicobacter pylori serology inversely correlated with the risk and severity of reflux esophagitis in Helicobacter pylori endemic area: A matched case-control study of 5,616 health check-up Koreans. J Neurogastroenterol Motil 2011; 17:267-273.

14. Chourasia D, Misra A, Tripathi S, Krishnani N, Ghoshal UC. Patients with Helicobacter pylori infection have less severe gastroesophageal reflux disease: a study using endoscopy, 24-hour gastric and esophageal pH metry. Indian J Gastroenterol 2011;30:12-21.

15. Wu JC, Sung JJ, Chan FK, et al. Helicobacter pylori infection is associated with milder gastro-oesophageal reflux disease. Aliment Pharmacol Ther 2000;14:427-432.

16. Kim N, Lee SW, Kim JI, et al. Effect of Helicobacter pylori eradication on the development of reflux esophagitis and gastroesophageal reflux symptoms: A nationwide multi-center prospective study. Gut Liver 2011;5:437-446.
17. Yaghoobi M, Farrokhyar F, Yuan Y, Hunt RH. Is there an increased risk of GERD after Helicobacter pylori eradication?: a metaanalysis. Am J Gastroenterol 2010;105:1007-1013.

18. Tefera S, Hatlebakk JG, Berstad AE, Berstad A. Eradication of Helicobacter pylori does not increase acid reflux in patients with mild to moderate reflux oesophagitis. Scand J Gastroenterol 2002;37:877883.

19. Song HJ, Shim KN, Yoon SJ, et al. The prevalence and clinical characteristics of reflux esophagitis in Koreans and its possible relation to metabolic syndrome. J Korean Med Sci 2009;24:197-202.

20. Nam SY, Choi IJ, Ryu KH, Kim BC, Kim CG, Nam BH. Effect of Helicobacter pylori infection and its eradication on reflux esophagitis and reflux symptoms. Am J Gastroenterol 2010;105:2153-2162.

21. Yim JY, Kim N, Choi SH, et al. Seroprevalence of Helicobacter pylori in South Korea. Helicobacter 2007;12:333-340.

22. Oh SW. Obesity and metabolic syndrome in Korea. Diabetes Metab J 2011;35:561-566.

23. The fourth Korea national health and nutrition examination survey (KNHANES IV). Seoul: Korea Centers for Disease Control and Prevention 2008.

24. Hongo M. Minimal changes in reflux esophagitis: red ones and white ones. J Gastroenterol 2006;41:95-99.

25. Armstrong D, Bennett JR, Blu AL, et al. The endoscopic assessment of esophagitis: a progress report on observer agreement. Gastroenterology 1996;111:85-92.

26. Yeom JS, Park HJ, Cho JS, Lee SI, Park IS. Reflux esophagitis and its relationship to hiatal hernia. J Korean Med Sci 1999;14:253-256.

27. Anand G, Katz PO. Gastroesophageal reflux disease and obesity. Rev Gastroenterol Disord 2008;8:233-239.

28. Cai N, Ji GZ, Fan ZN, et al. Association between body mass index and erosive esophagitis: a meta-analysis. World J Gastroenterol 2012;18:2545-2553.

29. Nandurkar S, Locke GR 3rd, Fett S, Zinsmeister AR, Cameron AJ, Talley NJ. Relationship between body mass index, diet, exercise and gastro-oesophageal reflux symptoms in a community. Aliment Pharmacol Ther 2004;20:497-505.

30. Ruigómez A, García Rodríguez LA, Wallander MA, JohanssonS, Graffner H, Dent J. Natural history of gastro-oesophageal reflux disease diagnosed in general practice. Aliment Pharmacol Ther 2004; 20:751-760.

31. Lagergren J, Bergström R, Nyrén O. No relation between body mass and gastro-oesophageal reflux symptoms in a Swedish population based study. Gut 2000;47:26-29.

32. Incarbone R, Bonavina L, Szachnowicz S, Saino G, Peracchia A. Rising incidence of esophageal adenocarcinoma in Western countries: is it possible to identify a population at risk? Dis Esophagus 2000;13:275-278.

33. Nilsson M, Lundegårdh G, Carling L, Ye W, Lagergren J. Body mass and reflux oesophagitis: an oestrogen-dependent association? Scand J Gastroenterol 2002;37:626-630.

34. Nam SY, Choi IJ, Nam BH, Park KW, Kim CG. Obesity and weight gain as risk factors for erosive oesophagitis in men. Aliment Pharmacol Ther 2009;29:1042-1052.

35. Corley DA, Kubo A, Zhao W. Abdominal obesity, ethnicity and gastro-oesophageal reflux symptoms. Gut 2007;56:756-762.

36. Peng S, Cui Y, Xiao YL, et al. Prevalence of erosive esophagitis and 
Barrett's esophagus in the adult Chinese population. Endoscopy 2009;41:1011-1117.

37. Gordon C, Kang JY, Neild PJ, Maxwell JD. The role of the hiatus hernia in gastro-oesophageal reflux disease. Aliment Pharmacol Ther 2004;20:719-732.

38. Avidan B, Sonnenberg A, Schnell TG, Sontag SJ. Risk factors for erosive reflux esophagitis: a case-control study. Am J Gastroenterol 2001;96:41-46.

39. Hyun JJ, Bak YT. Clinical significance of hiatal hernia. Gut Liver 2011;5:267-277.

40. Wang FW, Tu MS, Chuang HY, Yu HC, Cheng LC, Hsu PI. Erosive esophagitis in asymptomatic subjects: risk factors. Dig Dis Sci 2010;55:1320-1324.

41. Nocon M, Labenz J, Willicj SN. Lifestyle factors and symptoms of gastro-oesophageal reflux - a population-based study. Aliment Pharmacol Ther 2006;23:169-174.

42. Dore MP, Maragkoudakis E, Fraley K, et al. Diet, lifestyle and gender in gastro-oesophageal reflux disease. Dig Dis Sci 2008;53:20272032.

43. Wu P, Ma L, Dai GX, et al. The association of metabolic syndrome with reflux esophagitis: a case-control study. Neurogastroenterol Motil 2011;23:989-994.

44. Nocon M, Labenz J, Willicj SN. Lifestyle factors and symptoms of gastrooesophageal reflux - a population-based study. Aliment Pharmacol Ther 2006;23:169-174

45. Dore MP, Maragkoudakis E, Fraley K, et al. Diet, lifestyle and gender in gastrooesophageal reflux disease. Dig Dis Sci 2008;53:20272032. 